\title{
Martin Pâquet, Tracer les marges de la Cité. Étranger, Immigrant et État au Québec 1627-1981
}

\section{Simona Rossi}

\section{(2) OpenEdition}

1 Journals

\section{Edizione digitale}

URL: http://journals.openedition.org/studifrancesi/28217

DOI: 10.4000/studifrancesi.28217

ISSN: 2421-5856

\section{Editore}

Rosenberg \& Sellier

\section{Edizione cartacea}

Data di pubblicazione: 31 décembre 2006

Paginazione: 649

ISSN: 0039-2944

\section{Notizia bibliografica digitale}

Simona Rossi, « Martin Pâquet, Tracer les marges de la Cité. Étranger, Immigrant et État au Québec 1627-1987 », Studi Francesi [Online], 150 (L | III) | 2006, online dal 30 novembre 2015, consultato il 08 novembre 2020. URL : http://journals.openedition.org/studifrancesi/28217 ; DOI : https://doi.org/ 10.4000/studifrancesi.28217

\section{Questo documento è stato generato automaticamente il 8 novembre 2020}

\section{(c) (1)}

Studi Francesi è distribuita con Licenza Creative Commons Attribuzione - Non commerciale - Non opere derivate 4.0 Internazionale. 


\title{
Martin Pâquet, Tracer les marges de la Cité. Étranger, Immigrant et État au Québec 1627-1981
}

\author{
Simona Rossi
}

\section{NOTIZIA}

MARTIN PÂQUET, Tracer les marges de la Cité. Étranger, Immigrant et État au Québec 1627-1981, Montréal, Boréal, 2005, pp. 306.

1 Alla luce delle più che attuali problematiche legate all'immigrazione nella parte benestante del mondo occidentale, questo testo rappresenta uno spaccato storico e sociale di grande rilevanza. L'autore, Martin Pâquet, ricostruisce con sguardo lucido e talvolta impietoso la storia dell'immigrazione quebecchese di ben quattro secoli, dal 1627 al 1981. Egli si propone, nei sei capitoli che costituiscono la sua opera, di mostrare le variazioni concettuali che hanno subito nel corso del tempo i termini étranger e immigrant. Attraverso la trasformazione di queste due categorie, infatti, è possibile studiare l'importante mutamento dell'apparato politico quebecchese e l'evoluzione del pensiero collettivo. È con questo obiettivo, quindi, che ogni capitolo inquadra un periodo storico ben preciso, di cui illustra nel dettaglio l'atteggiamento dello Stato e degli individui nei confronti dell'Altro, lo Straniero, il Diverso.

2 Il primo capitolo, ad esempio, mostra quanto la realtà tra il 1627 e il 1760 fosse caratterizzata da rigide regole morali, linguistiche e religiose, le quali si rivelavano incredibilmente determinanti nell'ambito dell'accettazione sociale: in questo periodo l' étranger era dunque incarnato da colui che si dimostrava "porteur d'une éthique différente» (p. 34). Il secondo capitolo, invece, si concentra sul momento successivo alla cessione, da parte della madrepatria Francia, del territorio del Québec all'Inghilterra. Tale evento, che fece del Canada francese una colonia britannica a tutti gli effetti, produsse cambiamenti significativi in ogni ambito, compreso quello sociale. Lo 
straniero, infatti, colui che viene perseguito perché diverso, cominciò ad essere identificato in base al suo riconoscimento dell'autorità del nuovo sovrano e alla sua adesione alle leggi dello Stato. È solo a partire dal XIX secolo, come spiega l'autore nel terzo capitolo, che s'impose il moderno concetto di immigrant, il quale stabilisce ancor oggi che lo straniero è colui che è nato al di fuori del paese in cui risiede per motivi diversi. Nel momento in cui si cominciarono a privilegiare criteri più oggettivi e razionali, ossia l'origine e il luogo di nascita, vennero promulgate anche le prime leggi per il controllo del flusso migratorio. A questo proposito il quarto capitolo chiarisce che il Québec manifestò fin da subito una volontà d'integrazione armoniosa e solidale, la quale conobbe però una piena attuazione solo a partire dal 1853, quando lo Stato quebecchese cominciò ad occuparsi del benessere di tutti i suoi cittadini, compresi gli stranieri. Il quinto e il sesto capitolo, infine, s'immergono nell'era moderna: terminata la seconda guerra mondiale, si verificò in Québec una vera e propria invasione d'immigrati e il concetto d'integrazione acquistò rapidamente un valore concreto. La diversità venne concepita sempre più come una ricchezza e lo Stato offrì agli stranieri un consistente aiuto non solo sul piano economico, ma anche psicologico, con programmi speciali che miravano a potenziare l'autostima degli immigrati e il loro sentimento di appartenenza nei confronti della nuova patria. Nel 1968 nacque poi il ministero dell'immigrazione: è grazie al suo operato che oggi gli immigrati possono contare sul riconoscimento di una piena identità sociale.

Come si può notare, il profondo legame esistente tra la situazione storica e sociale di un paese e i suoi concetti d'immigrant e étranger, rende questi ultimi instabili e mutevoli. È proprio per questo motivo che comprendere le loro variazioni, le modalità di costruzione sociale a cui sono soggetti e le nuove e diverse sfaccettature che assumono nel corso del tempo, significa anche comprendere «l'ordre des choses qui structure le champ politique, qui attribue aux différents acteurs une position dominante ou dominée, qui trace les marges de la Cité» (p. 18). Tale è evidentemente l'obiettivo di questo volume, che si impone per efficacia ed attualità. 